\title{
A large outbreak of conjunctivitis on Mayotte Island, France, February to May 2012
}

T Lernout (tinne.lernout@ars.sante.fr) ${ }^{1}, 0$ Maillard ${ }^{2}$, S Boireaux ${ }^{2}$, L Collet $^{2}$, L Filleul ${ }^{1}$

1. Regional office of the French Institute for Public Health Surveillance (Institut de veille sanitaire-InVS), Mayotte, France

2. Hospital Centre of Mayotte, Mayotte, France

Lernout T, Maillard O, Boireaux S, Collet L, Filleul L. A large outbreak of conjunctivitis on Mayotte Island, France, February to May 2012. Euro Surveill. 2012;17(23): pii=20192. Available online: http://www.eurosurveillance.org/ViewArticle. aspx?Articleld=20192

Article submitteed on 1 June 2012 / published on 7 June 2012

From February to May 2012, Mayotte experienced an outbreak of acute conjunctivitis with over 12,000 estimated cases, causing a significant burden on the primary healthcare system. It was most certainly caused by a coxsackievirus, as documented by isolation from a symptomatic traveller from the Comoros Islands in France. Tropical climate and poor hygiene conditions facilitate the spread of infectious diseases on Mayotte and in the region with risk of further exportation to mainland France and Europe.

There is anecdotal evidence that large epidemics of conjunctivitis occurred on Mayotte in the past, but no outbreak had been reported for over 15 years. In mid February 2012, several general practitioners (GP) belonging to a sentinel surveillance network reported an increase in patients consulting with acute conjunctivitis. Patients presented clinically with sudden onset of redness, marked swelling and pain often in both eyes. All were living in the town of Sada, on the east cost of Grande Terre [1].

Mayotte, located in the northern Mozambique Channel in the Indian Ocean (Figure 1), is a French overseas department with a maritime tropical climate. The hot and humid rainy season usually starts in November and lasts until May. Mayotte is made up of two islands, Grande Terre and Petite Terre with a surface of around $374 \mathrm{~km}^{2}$. The island is very densely populated and has around 200,000 inhabitants of whom $53 \%$ are under 20 years of age [2]. General hygiene and living conditions are poor. Given the proximity of Mayotte and the Comoros, both part of the Comoros archipelago, travel (legal and illegal movements) between the islands is frequent.

\section{Outbreak description}

To describe the outbreak of acute conjunctivitis and evaluate its impact on the healthcare system, two sources of data were used (i) the number of conjunctivitis cases and total number of outpatients seen by GPs geographically spread throughout the island, who belong to a sentinel GP network, and (ii) the numbers of topical antibiotics or steroid treatments distributed by the 17 public health centres on the island, provided by the central pharmacy of the hospital centre of Mayotte.

The GP sentinel surveillance system was set up in Mayotte in 2009, for influenza-like illness by the regional office (Cire) of the French Institute for Public Health Surveillance (Institut de Veille Sanitaire) as response to the influenza $\mathrm{A}\left(\mathrm{H}_{1} \mathrm{~N}_{1}\right)$ pdm 2009 pandemic [3]. It covers $36 \%$ of the primary care facilities in Mayotte and has since been extended to surveillance of diarrhoeal diseases and asthma as well as other syndromes, whenever needed to describe epidemics. As soon as the increase in the number of patients presenting with conjunctivitis was observed, the sentinel GPs were requested to report weekly data on the number of cases to the Cire. Information on sex and age was not requested.

\section{FIGURE 1}

Location of Mayotte

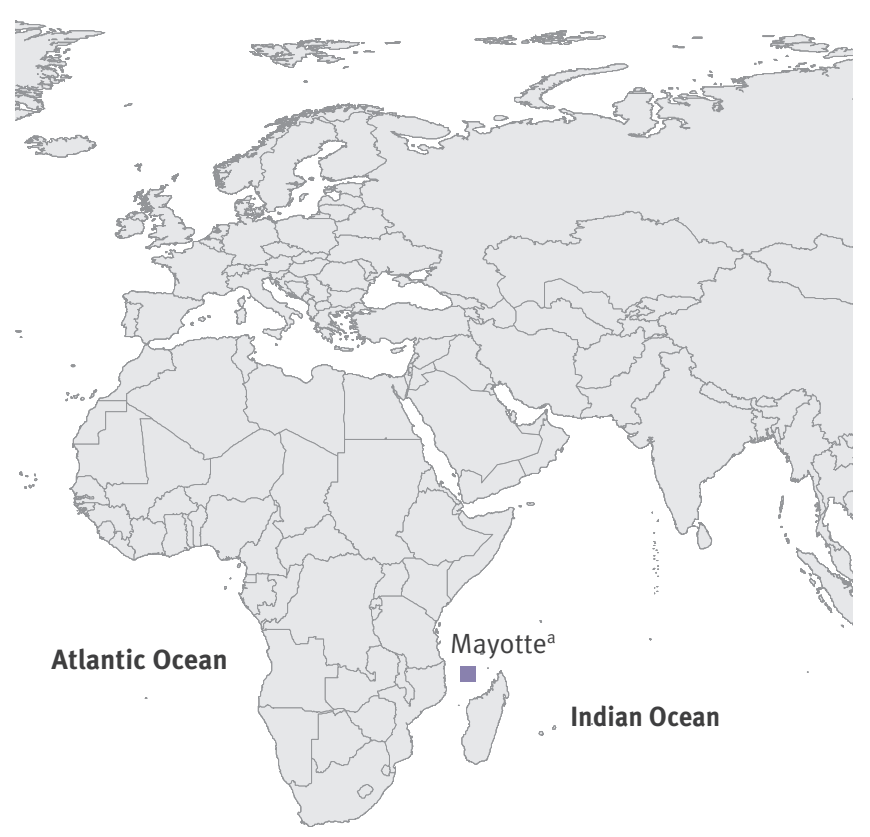

${ }^{a}$ Mayotte lies within the Comoros archipelago. 


\section{FIGURE 2}

Epidemic curve of conjunctivitis cases, based on the number of patients consulting sentinel general practitioners, Mayotte, February-May $2012(\mathrm{n}=2,100)$

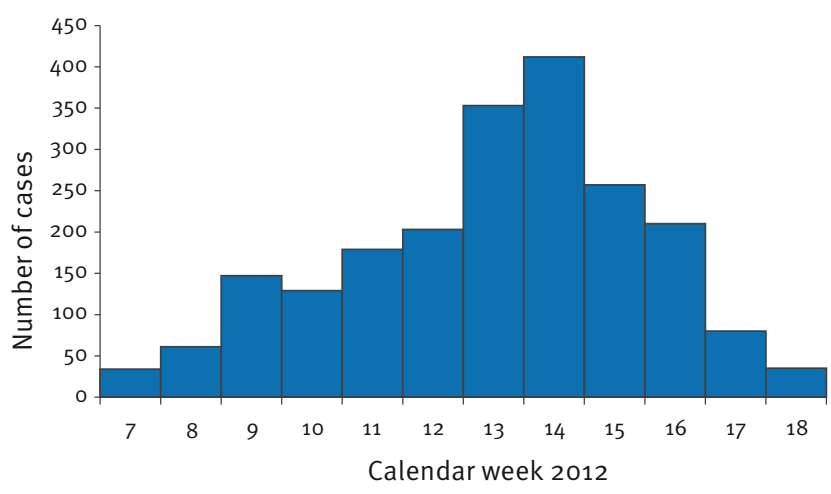

The epidemic started in week 7 (mid February) reached a peak at the end of March with 353 cases reported by sentinel GPs in week 13 and 412 cases in week 14 and ended in May (Figure 2). It lasted 10 weeks in total and reached normal level in week 19 . From the east coast of Grande Terre where the outbreak started, it spread progressively across the territory, first towards the south and then to the north and the smaller island of Petite Terre (Figure 3).

In the sentinel sites in healthcare centres, 2,100 cases were recorded. Conjunctivitis patients represented up to $45 \%$ of the total activity at these centres during the epidemic period. The weekly distribution of topical treatments was in line with the epidemiological curve. No severe cases were reported and no cases were hospitalised.
The total number of conjunctivitis cases consulting one of the public healthcare centres on Mayotte over the 10 -week period is estimated at more than 12,000 individuals, around $6 \%$ of the total population. The weekly number of conjunctivitis patients consulting any healthcare centres ranged from 660 to almost 1,700 , reaching a peak at week 14 with $23 \%$ of the total number of consultations. These estimations neither include patients consulting a private GP $(n=21)$ nor those who did not seek medical care.

\section{Laboratory investigations}

Laboratory analysis on 13 conjunctival swabs randomly collected by sentinel GPs did not identify any particular bacteria. Of three swabs tested for viruses by a laboratory in mainland France, two were positive for enterovirus, not further typed.

\section{Public health measures}

Although general living conditions of the population of Mayotte are poor, $82 \%$ of the households have a television [4]. Public health messages on hygiene practices have been broadcasted through local media, both radio and television [5]. Since $40 \%$ of the population are school-aged children, communication on preventive measures also took place at public primary and secondary schools.

\section{Conclusions}

Due to the tropical climate, high population density and poor hygiene standards, the population of Mayotte is largely exposed to infectious diseases. Although no severe cases have been reported, the outbreak of conjunctivitis that occurred from February to May caused widespread morbidity across the island with an important burden on the primary healthcare system.

\section{FIGURE 3}

Proportion of conjunctivitis cases compared to total number of patients consulting sentinel general practitioners by week and by location, Mayotte, February-May 2012

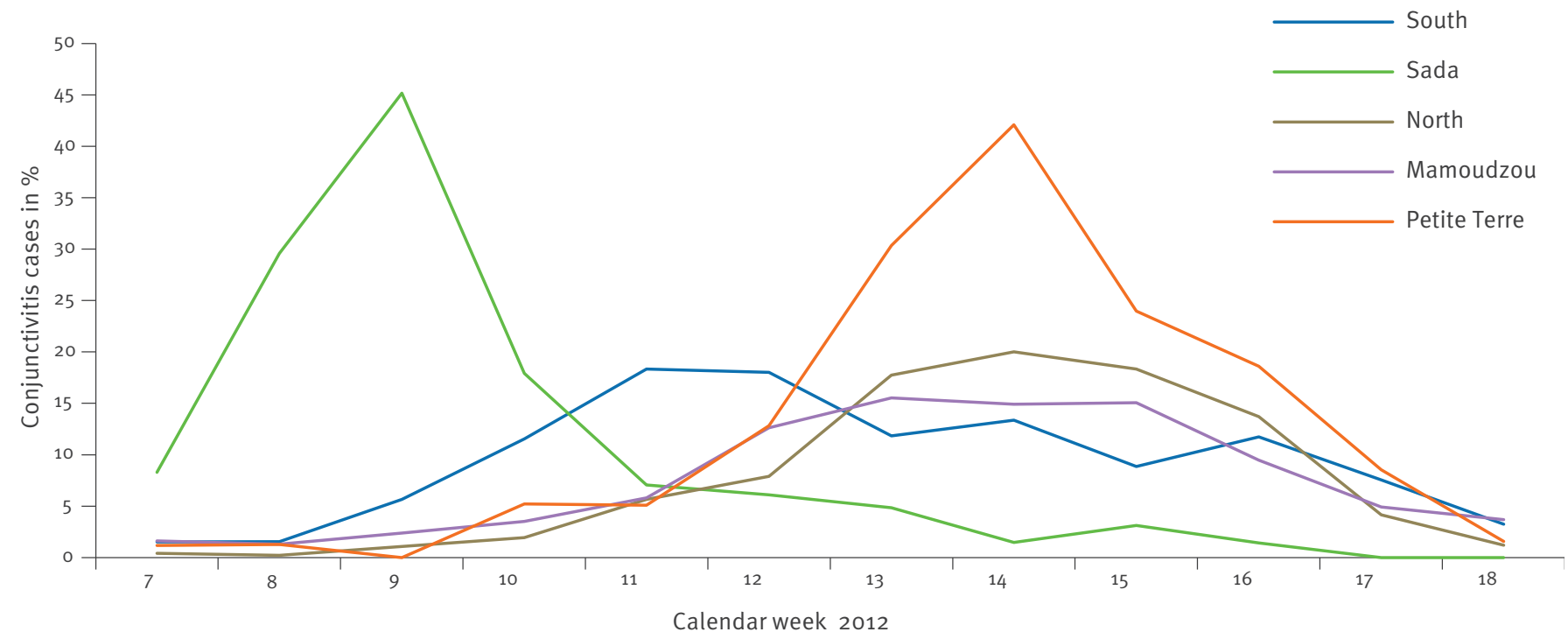


The outbreak on Mayotte is in line with what has been described elsewhere. Epidemics of viral conjunctivitis are mostly attributed to adenoviruses and enteroviruses (including coxsackievirus A) [6]. They occur mainly in tropical countries during hot, rainy seasons and in densely populated areas [7].

In May 2012, coxsackievirus A24 was isolated from a traveller with haemorrhagic conjunctivitis, returning from Comoros Island [8], where an outbreak of conjunctivitis was described by the local press [9]. This supplementary information leads us to conclude that the outbreak in Mayotte is most certainly caused by the same virus which is circulating in the Comoros archipelago.

The frequent movement of people between Mayotte and the Comoros Islands facilitates the spread of infectious diseases in the region and there is a risk of further exportation to mainland France and Europe through returning travellers.

\section{References}

1. Institut de Veille Sanitaire. Point épidémiologique. Epidémie de conjonctivite à Mayotte. [Conjunctivitis epidemic in Mayotte].

Point épidémiologique 15. CIRE Océan indien; 22 Mar 2012. French. Available from: http://www.invs.sante.fr/fr/content/ download/33467/166831/version/6/file/pe_conjonctivites_ mayotte_220312.pdf

2. Institut national de la statistique et des études économiques (Insee). Répartition de la population par âge aux recensements - RP 07. [Population of Mayotte by age, 2007. Population census 2007]. Insee. [Accessed 30 May 2012]. French. Available from: http://www.insee.fr/fr/themes/tableau. asp?reg_id=27\&ref_id=popopo01

3. Lernout $T$, Durquety $E$, Chollet $P$, Helleisen $F$, Javaudin $G$, Lajoinie G, et al. Influenza $A\left(\mathrm{H}_{1} \mathrm{~N}_{1}\right) \mathrm{v}_{2009}$ surveillance on Mayotte Island: the challenge of setting up a new system facing the pandemic. Bull Soc Pathol Exot. 2011;104(2):114-8. French.

4. Institut national de la statistique et des études économiques (Insee). Taux d'équipement des ménages par commune [Equipment of households in Mayotte. Population census 2007]. Insee. [Accessed 6 Jun 2012]. French. Available from: http://www.insee.fr/fr/insee_regions/mayotte/themes/ dossiers/tem/tem_5-1-equipement-menages.pdf

5. Agence de Santé Océan Indien. Epidémie de conjonctivite à Mayotte: rappel des précautions à prendre. [Conjunctivitis epidemic in Mayotte: reminder on precautions]. 13 Mar 2012. French. Available from: http://www.ars.ocean-indien.sante.fr/ Epid-mie-de-conjonctivite-Ma.130932.0.html

6. Centers for Disease Control and Prevention (CDC). Notes from the field: acute hemorrhagic conjunctivitis outbreaks caused by coxsackievirus A24v Uganda and southern Sudan, 2010. MMWR Morb Mortal Wkly Rep. 2010;59(32):1024.

7. Hierholzer JC, Hilliard KA, Esposito JJ. Serosurvey for "acute hemorrhagic conjunctivitis" virus (Enterovirus 70) antibodies in the Southeastern United States, with review of the literature and some epidemiologic implications. Am J Epidemiol. 1975;102(6):533-44

8. Aubry C, Gautret P, Nougairede A, Dussouil AS, Botelho-Nevers E, Zandotti C, et al. 2012 outbreak of acute haemorrhagic conjunctivitis in Indian Ocean Islands: identification of Coxsackievirus $\mathrm{A} 24$ in a returned traveller. Euro Surveill. 2012;17(22): pii=20185. Available from: http://www. eurosurveillance.org/ViewArticle.aspx?Articleld =20185

9. Al-watwan. Attention, "Matso-matso" est de retour à Ndzuwani! [Attention, "Matso-matso" is back in Ndzuwani!]. Alwatwan no. 1942; 25 Apr 2012. French. Available from: http:// www.alwatwan.net/index.php?home=actu.php\&actu_id=3984 